\title{
Cause and Effect Relationships between Emotional Intelligence's Components, Organizational Commitment and Job Satisfaction using Fuzzy DEMATEL Method: Case Study of Iranian Central Oil Fields Company
}

\author{
1Sirous Amirghodsi \\ ${ }^{2}$ Ali Bonyadi Naeini \\ 1,2Iran University of Science and Technology (IUST), Tehran, Iran
}

Doi:10.5901/mjss.2016.v7n4s2p17

\section{Abstract}

\begin{abstract}
The present research investigates cause and effect relationships of emotional intelligence's components, on one side, and organizational commitment and job satisfaction, on the other side using fuzzy DEMATEL method in Iranian Central Oil Fields Company (I.C.O.F.C). The research is of applied-developmental, descriptive and survey type. The population consisted of 15 ICOFC's experts that were selected based on theoretical saturation. To answer the research question, a particular fuzzy DEMATEL questionnaire was designed and the data analysis was conducted using fuzzy DEMATEL technique. The results showed that self-awareness was the strongest cause variable and job satisfaction as the second strong cause variable. Among the components of emotional intelligence, the strongest cause variable was self-motivation had a considerable effect on organizational commitment. In fact, the results state that self-motivation is like an engine which upon proper utilization, could boost organizational commitment, empathy, self-control and even social skills.
\end{abstract}

Keywords: Emotional intelligence, Organizational commitment, Job satisfaction, Fuzzy DEMATEL method

\section{Introduction}

Human resources, which are committed to the goals and values of their organization, not only are regarded as an advantage of an organization over another, but also as a sustainable competitive advantage for many of organizations (Wooldridge, 2000). On the other side, human resource with a low sense of belonging, loyalty and commitment, not only does not move toward the goals of the organization, but also weakens the spirit of collaboration by creating a culture of being indifferent to the problems and concerns of the organization, which ultimately delays the success of the organization or prevent it (Jordan, Ashkanasy, Härtel, \& Hooper, 2002).

If an effective human resource is intended and a good level of job productivity is targeted, one should utilize psychological principles and findings. In this regard, emotional intelligence could provide a pleasant work environment and affect job satisfaction of employees, effective management and advancement of the organization, since a high level of emotional intelligence increases performance, strategic understanding and job satisfaction, is of a positive role in positioning and decreases employee problems. Golman believes that not only managers and directors need a good level of emotional intelligence, but everyone working in an organization. An employee who could increase his emotional intelligence abilities or reinforce his skills in a well-prepared organizational context, could naturally identify his needs better and more balanced and reach a higher satisfaction (Schlechter \& Strauss, 2008).

Today, science has discovered the power of emotions and feelings in human life and is engaged with discovery and explanation of its role in human activities and behaviors. Emotional intelligence covers emotions and their applications in human communications, understanding self and other emotions, and positive utilization of emotions (Gholami, Shams, \& Amoozadeh, 2013). The ability of understanding and managing one's self and other's emotions and feelings would increase engagement and commitment of employees, promote motivation and productivity of individuals and ultimately provoke job satisfaction and higher profitability of the organization (Taboli et al., 2013). In recent years, studies have changed their way from logical intelligence toward emotional intelligence. Accordingly, this concept was introduced into the management literature since 1990s. the concept of emotional intelligence is applied into organizations and for human resource development to emphasize important needed skills in work environments other than professional capabilities needed (Chan, 2006). However, despite emphases on adoption of collaborative approach to management of organization, one unfortunately still witnesses the dominance of mechanical organizational structures and authoritarian 
approaches in countries like Iran. This could be attributed to cultural impacts and mistrust to workforce and also an overemphasis on increase of effectiveness and profitability in organizations. The relationships between emotional intelligence, organizational effectiveness and leadership are of great importance. Some managers and employees are not able to get feedback or properly give feedbacks due to their weak relations with others. Another prevalent problem is low organizational commitment and job satisfaction of employees in organizations and also lack of ability to effectively communicate with clients. These problems are of great adverse effects on decrease of organizational productivity in longterm, and thus studying this topic and providing effective solutions would be valuable and useful.

Due to the importance of the variables of organizational commitment and job satisfaction in increasing of productivity, service quality, effectiveness, employee motivation and decreasing work leave, it is important to study factors affecting them, including emotional intelligence. People having higher emotional intelligence are of a greater commitment to their job, which in turn predicts job satisfaction (Othman \& Anugerah, 2009). In fact, emotional intelligence is a useful predictor of job satisfaction and organizational commitment (Öztürk \& Deniz, 2008). Today, many of researchers seek to deeply understand the factors affecting commitment and job satisfaction of employees and also the utilization from. The literature review showed that researches are mostly focused on cognitive aspects of employee performance and unfortunately the effects of emotional aspects are vastly neglected in organizational behavior researches. Of course, some leadership theories have bolded the importance of emotional and social intelligence, but as it was aforementioned, there are little empirical evidences about the dimensions of emotional intelligence of employees and its impact on attitude and job behaviors. On this basis, studying mutual influences of emotional intelligence's components, organizational commitment and job satisfaction seems necessary in organizations such as Iranian Central Oil Fields Company (I.C.O.F.C). These issues altogether indicate the importance of the present research topic.

\section{Literature Review}

The variables used in this research are emotional intelligence, job satisfaction and organizational commitment. In the followings, definitions of the variables are provided.

Emotional intelligence: It is defined as the ability to perceive emotions, to access and generate emotions to assist thought, to understand emotions and emotional knowledge, and to reflectively regulate emotions to promote emotional and intellectual growth (Mayer \& Salovey, 1997).

Job satisfaction: It is defined as a feeling of an individual toward his/her job (Qasim, Cheema, \& Syed, 2012). Job satisfaction points to the pleasure brought about by working, doing a work better, happiness and joy about work, and receiving appropriate incentive for individual efforts in a job (Bakotić \& Babić, 2013).

Organizational commitment: Baker defines it as the tendency of an individual to get engaged and participate in organizational processes and activities with the understanding of the related opportunity cost. Porter has defined organizational commitment as the intensity of personal identification of an individual based on his/her organization and engagement and participation therein (Kay, 2007).

In a recent study, Bazvand, Kashef, \& Esmaeili (2013) in their study about the association of emotional intelligence, organizational commitment and job satisfaction of the staff of Physical Education Department of Lorestan province exhibited a positive significant relationship between emotional intelligence, on one side, and job satisfaction and organizational commitment, on the other side. There was also a positive significant relationship between job satisfaction and organizational commitment. The regression results depicted that the roles of the feeling clarification component and attention to feelings were statistically significant in prediction of organizational commitment and job satisfaction. Nazarian Madavani \& Mokhtari Dinani (2013) have also investigated if there is any relationship between job satisfaction, organizational commitment, and emotional intelligence of the staff of the physical education departments of universities located in Tehran. The results displayed significant relationships between emotional intelligence and job satisfaction, between emotional intelligence and organizational commitment, and finally between job satisfaction and organizational commitment. Based on their research, there is also a significant association between emotional intelligence, on one side, and job satisfaction and organizational commitment, on the other side, such that emotional intelligence explained about $19 \%$ and $17 \%$ of the variances of job satisfaction and organizational commitment, respectively. According to their suggestions, delegating more authority to competent employees, strengthening teamwork spirit in individuals and developing appropriate alternatives for widespread application of such spirit would be of effect in solidification of the organizational commitment of the staff of the physical education departments of universities located in Tehran.

Utami, Bangun, \& Lantu (2014) conducted a study entitled understanding the role of emotional intelligence and trust to the relationship between organizational politics and organizational commitment. The results indicated that employee perception of organizational policies is associated with lower organizational trust and commitment. High trust of 
employees was also found to be in a significant correlation with their high organizational commitment. The results also depicted that trust has a mediating role in the relationship between understanding organizational policies and organization commitment. Likewise, emotional intelligence was found to have a mediating role in the relationship between the two other variables.

Furthermore, the research of Alavi, Mojtahedzadeh, Amin, \& Savoji (2013) in Ramin thermal power plant has shown that there is a significant association between emotional intelligence and organizational commitment of employees. In another study entitled job satisfaction as a mediator of the relationship between emotional intelligence and organizational commitment of the employees of Kerman University, Taboli et al. (2013) illustrated that job satisfaction was of a significant mediating role in this regard. Their results also confirmed that there is a positive significant association between emotional intelligence and organizational commitment, which is of a great importance.

\section{Research Method}

This study is a descriptive-survey and applied-developmental research. Fuzzy DEMATEL method was chosen because it is of a good preciseness and that it has not yet been used in the studies about emotional intelligence and its relationship with job satisfaction and organizational commitment, although it could have been of application in solving problems of organizations.

The population under study was consisted of the experts of Iranian Central Oil Fields Company (I.C.O.F.C). The temporal scope of the research dates back to May 2014 to Sep 2014. The sample size was determined using theoretical saturation method which equaled 15 heads. To gather required information and data, a questionnaire was designed to be used in fuzzy DEMATEL technique.

In the following, the steps of the fuzzy DEMATEL method are described:

In fuzzy DEMATEL method, judgments of experts are utilized which contain ambiguous linguistics statements. To remove such ambiguities and homogenizing the linguistics terms, fuzzifying the terms is preferred. To solve this problem, Lin \& Wu (2008) have provided a model which utilizes DEMATEL method in a fuzzy context. The steps of fuzzy DEMATEL method, which are provided below, are the same as non-fuzzy DEMATEL with the difference that the fuzzy linguistic scaling proposed by Li (1999).

- Step 1: Defining decision making goal and establishment of a committee;

- Step 2: Developing evaluation criteria and designing a fuzzy linguistic scale;

In this step, a set of criteria would be determined for the purpose of evaluation. Evaluation criteria possess the features of causal relationships and multitude of complexities. To utilize a structural model, the criteria should be grouped under cause and effect types. In this sense, DEMATEL is an appropriate technique. Lin \& Wu (2008) have worked on the development of DEMATEL technique to be used in group decision making, in which the fuzzy linguistic scales presented by Li (1999) are used for elimination of estimated human ambiguities. Differences in degree of influence are shown by five linguistic terms and their respective fuzzy triangular numbers, as illustrated in Table 1.

Table 1: Linguistic terms and values in fuzzy DEMATEL technique (Lin \& Wu, 2008)

\begin{tabular}{lcc}
\hline Linguistic variables & Influence Score & Triangular Fuzzy Number \\
\hline No Influence $(\mathrm{NO})$ & 0 & $(0,0,0.25)$ \\
Very Low Influence $(\mathrm{VL})$ & 1 & $(0,0.25,0.25)$ \\
Low Influence $(\mathrm{L})$ & 2 & $(0.25,0.5,0.75)$ \\
High Influence $(\mathrm{H})$ & 3 & $(0.5,0.75,1)$ \\
Very High Influence $(\mathrm{VH})$ & 4 & $(0.75,1,1)$ \\
\hline
\end{tabular}

- Step 3: Gathering evaluation outcomes performed by decision-makers and averaging them;

As noted, in order to measure the relationship between criteria $C=\left\{c_{i} \mid i=1,2, \ldots, n\right\}$, a decision-making group consisted of $p$ experts should be asked to carry out a paired comparison of linguistic terms. After that, $p$ fuzzy matrices $\tilde{z} 1 \tilde{z}^{2}{ }^{\prime} \ldots \tilde{z} p$ would be obtained corresponding to each expert and the fuzzy triangular numbers associated with its elements.

Then, average of the matrices is calculated using Eq. (1) to Eq. (3). Having $\tilde{N}=(l, m, u)$, the following formulae would be obtained:

$$
\begin{aligned}
& \mathrm{K} * \tilde{N}=(\mathrm{kl}, \mathrm{km}, \mathrm{ku}) \\
& \tilde{\mathrm{N}}_{1}+\tilde{N}_{2}=\left(\mathrm{l}_{1}+\mathrm{l}_{2}, \mathrm{~m}_{1}+\mathrm{m}_{2}, \mathrm{u}_{1}+\mathrm{u}_{2}\right)
\end{aligned}
$$


(2)

$\tilde{Z}=\frac{\tilde{Z}^{1}+\tilde{z}^{2}+\ldots+\tilde{Z}^{P}}{P}$

The fuzzy matrix $Z$ is called initial direct-relation fuzzy matrix. For the sake of simplicity, matrix $Z$ is obtained as:

$\tilde{Z}=\left[\begin{array}{cccc}0 & \tilde{Z}_{12} \cdots & \tilde{Z}_{1 \mathrm{n}} \\ \vdots & \ddots & \vdots \\ \tilde{Z}_{\mathrm{n} 1} & \tilde{Z}_{\mathrm{n} 2} \cdots & 0\end{array}\right]$

As formulae (1) and (2) show, $\tilde{Z}_{\mathrm{ij}}=\left(\mathrm{l}_{\mathrm{ij}}, \mathrm{m}_{\mathrm{ij}}, \mathrm{u}_{\mathrm{ij}}\right)$ are triangular fuzzy numbers. Also if necessary, the ij elements of $\tilde{Z}_{\mathrm{ij}}(\mathrm{i}=1,2, \ldots, \mathrm{n})$ are considered as triangular fuzzy numbers of $(0,0,0)$.

- Step 4: Determining and analyzing a structural model;

The linear scale conversion used here is a kind of normalization aimed at conversion of criteria's scale into a comparable one.

$$
\begin{aligned}
& \tilde{a}_{\mathrm{i}}=\sum_{j=1}^{n} \tilde{Z}_{\mathrm{ij}}=\left(\sum_{j=1}^{n} \mathrm{l}_{i j}, \sum_{j=1}^{n} \mathrm{~m}_{i j}, \sum_{j=1}^{n} \mathrm{u}_{i j}\right) \\
& \text { And } \mathrm{r}=\max _{1 \leq i \leq n}\left(\sum_{j=1}^{n} \mathrm{u}_{i j}\right)
\end{aligned}
$$

Consequently, normalized direct-relation fuzzy matrix is obtained which is denoted by $\tilde{X}$, as below:

$$
\widetilde{\mathrm{X}}=\left[\begin{array}{cccc}
\widetilde{\mathrm{X}}_{11} & \widetilde{\mathrm{X}}_{12} & \cdots & \widetilde{\mathrm{X}}_{1 n} \\
\vdots & \ddots & \vdots \\
\widetilde{\mathrm{X}}_{n 1} & \widetilde{\mathrm{X}}_{n 2} \cdots & \widetilde{\mathrm{X}}_{n n}
\end{array}\right] \text { where } \tilde{X}_{\mathrm{ij}}=\frac{\tilde{Z}_{\mathrm{ij}}}{r}=\left(\frac{\mathrm{L}_{i j}}{r}, \frac{\mathrm{M}_{i j}}{r}, \frac{\mathrm{U}_{i j}}{r}\right)
$$

The normalized method applied above is similar to the one used in fuzzy TOPSIS (Technique for Order Preference by Similarity to Ideal Solution) technique. To calculate the overall relation fuzzy matrix $\widetilde{T}$, one should be confident about the convergence of $\lim _{k \rightarrow \infty} \tilde{X}^{k}=0$ in its progress path to infinity. For calculation of $\tilde{X}_{X}^{k}$, an estimation of the below formulae should be used for a multiplication of two triangular fuzzy numbers.

$\widetilde{\mathrm{N}}_{1} \times \widetilde{\mathrm{N}}_{2} \cong\left(\mathrm{l}_{1} \times \mathrm{l}_{2}, \mathrm{~m}_{1} \times \mathrm{m}_{2}, \mathrm{u}_{1} \times \mathrm{u}_{2}\right)$

Therefore, elements $\tilde{X} k$ are also triangular fuzzy numbers.

Having $\tilde{X}_{\mathrm{ij}}=\left(\mathrm{l}_{\mathrm{ij}}, \mathrm{m}_{\mathrm{ij}}^{\prime}, \mathrm{u}_{\mathrm{ij}}^{\prime}\right)$, the three matrices which their elements are extracted from $\tilde{X}$, are defined as:

$$
\begin{aligned}
& \mathrm{X}_{\mathrm{l}}=\left[\begin{array}{cccc}
0 & \mathrm{l}_{12}^{\prime} & \cdots & \mathrm{l}_{1 \mathrm{n}}^{\prime} \\
\vdots & \ddots & \vdots \\
\mathrm{l}^{\prime}{ }_{\mathrm{n} 1} & \mathrm{l}^{\prime}{ }_{\mathrm{n} 2} & \cdots & 0
\end{array}\right], \mathrm{X}_{\mathrm{m}}=\left[\begin{array}{cccc}
0 & \mathrm{~m}^{\prime}{ }_{12} & \cdots & \mathrm{m}^{\prime}{ }_{1 \mathrm{n}} \\
\vdots & \ddots & & \vdots \\
\mathrm{m}^{\prime}{ }_{\mathrm{n} 1} & \mathrm{~m}^{\prime}{ }_{\mathrm{n} 2} & \cdots & 0
\end{array}\right] \text {, } \\
& \mathrm{X}_{\mathrm{u}}=\left[\begin{array}{cccc}
0 & \mathrm{u}_{12}^{\prime} & \cdots & \mathrm{u}_{1 \mathrm{n}}^{\prime} \\
\vdots & \ddots & & \vdots \\
\mathrm{u}_{\mathrm{n} 1}^{\prime} & \mathrm{u}_{\mathrm{n} 2}^{\prime} & \cdots & 0
\end{array}\right]
\end{aligned}
$$

According to the determined position, the overall relation fuzzy matrix is defined as:

$\widetilde{\mathrm{T}}=\lim _{\tilde{\tilde{t}} \rightarrow \infty}\left(\tilde{X}_{\tilde{\mathrm{t}}}^{1+\tilde{X}^{2}} 2+\cdots+\tilde{X}^{k}\right)$

$\left[\begin{array}{cccc}\tilde{\mathrm{t}}_{11} & \tilde{\mathrm{t}}_{12} & \cdots & \tilde{\mathrm{t}}_{1 n} \\ \vdots & \ddots & \vdots \\ \tilde{\mathrm{t}}_{n 1} & \tilde{\mathrm{t}}_{n 2} \cdots & \tilde{\mathrm{t}}_{n n}\end{array}\right]$ where $\tilde{\mathrm{t}}_{i j}=\left(\mathrm{l}^{\prime \prime}{ }_{\mathrm{ij}}, \mathrm{m}^{\prime \prime}{ }_{\mathrm{ij}}, \mathrm{u}^{\prime \prime}{ }_{\mathrm{ij}}\right)$

$$
\begin{aligned}
& {\left[l^{\prime \prime}{ }_{i j}\right]=X_{l} \times\left(I-X_{l}\right)^{-1}\left[m^{\prime \prime}{ }_{i j}\right]=X_{m} \times\left(I-X_{m}\right)^{-1}} \\
& {\left[\mathrm{u}^{\prime}{ }_{\mathrm{ij}}\right]=\mathrm{X}_{\mathrm{u}} \times\left(\mathrm{I}-\mathrm{X}_{\mathrm{u}}\right)^{-1}}
\end{aligned}
$$

Now by having $\widetilde{T}$ obtained, calculation of $\left(\tilde{R}_{i}+\tilde{J}_{i}\right)$ becomes simple, since $\tilde{R}_{i}$ and $\tilde{J}_{i}$ are sum of the rows and columns of $\widetilde{T}$ respectively.

To defuzzify the data, Best Non-Fuzzy Performance (BNP) technique was utilized according to below formulae (Hsieh, Lu, \& Tzeng, 2004):

$$
B N P=l+\frac{(u-l)+(m-l)}{3}
$$

Then, a causal diagram would be obtained in which the horizontal axis of $\left(\mathrm{R}_{i}+\mathrm{J}_{\mathrm{i}}\right)$ def is called "superiority" axis, while "dependence" axis denotes the vertical axis of $\left(\mathrm{R}_{i}-\mathrm{J}_{\mathrm{i}}\right)$ def. the horizontal axis shows superiority of the importance of criteria, while vertical axis of dependence divides criteria into two groups of cause and effect criteria. In general, if ( $\left.\mathrm{R}_{\mathrm{i}}-\mathrm{J}_{\mathrm{i}}\right)$ def is positive, the criterion would belong to cause group and is definitely an influencer element. But if $\left(R_{i}-J_{i}\right)$ def takes a negative value, it belongs to effect group and is considered an influenced element. In addition, $\left(\mathrm{Ri}_{\mathrm{i}}+\mathrm{J}_{\mathrm{i}}\right)$ def stands for the sum of an element (across horizontal axis), including both influencer and influenced types. Therefore, causal diagrams illustrate complex causal relationships of criteria in a structural model and provide a valuable insight for solving problems. Furthermore, with the aid of causal diagrams, one could make appropriate decisions by recognizing differences between 
influencer (cause) and influenced (effect) criteria.

\section{Findings}

To collect the information and data needed for the present research, the questionnaire related to fuzzy DEMATEL technique was used. The managers and experts of the Iranian Central Oil Fields Company (I.C.O.F.C) fulfilled the questionnaire after receiving required explanations and guides. In fact, experts should have completed a matrix in which the effect of each row on all columns has been shown by five linguistic terms and symbols of $\mathrm{NO}$ (no influence), VL (very low influence), L (low influence), H (high influence) and VH (very high influence). Table 2 provides a sample matrix fulfilled by an expert.

Table 2: Sample matrix representing fulfilled questionnaire by an expert

\begin{tabular}{lcccc}
\hline Self-awareness & Self-control & Self-motivation & Empathy & Social Skills \\
\hline Self-awareness & $\mathrm{NO}$ & $\mathrm{L}$ & $\mathrm{L}$ & $\mathrm{VH}$ \\
Self-control & $\mathrm{L}$ & $\mathrm{NO}$ & $\mathrm{H}$ & $\mathrm{VH}$ \\
Self-motivation & $\mathrm{H}$ & $\mathrm{H}$ & $\mathrm{NO}$ & $\mathrm{VH}$ \\
Empathy & $\mathrm{NO}$ & $\mathrm{VH}$ & $\mathrm{H}$ & $\mathrm{NO}$ \\
Social Skills & $\mathrm{L}$ & $\mathrm{VH}$ & $\mathrm{NO}$ & $\mathrm{H}$ \\
\hline
\end{tabular}

Application of DEMATEL technique in fuzzy state is as stated below:

- Step 1: Determining decision-making goals and establishment of a committee;

- Step 2: Development of evaluation criteria and design of a fuzzy linguistic scale; In this step, the identified criteria are provided to experts to be weighed in a fuzzy manner via a questionnaire.

- Step 3: Obtaining evaluations of decision-makers and averaging them;

The prepared questionnaires were provided to the experts and after collection of the questionnaires, the mean of the judgements of the experts were calculated, as could be seen from Table 3.

Table 3: Average of expert opinions

\begin{tabular}{lccccccc}
\hline & $\begin{array}{c}\text { Self- } \\
\text { awareness }\end{array}$ & $\begin{array}{c}\text { Self- } \\
\text { management }\end{array}$ & $\begin{array}{c}\text { Self- } \\
\text { motivation }\end{array}$ & Empathy & $\begin{array}{c}\text { Social } \\
\text { skills }\end{array}$ & $\begin{array}{c}\text { Organizational } \\
\text { commitment }\end{array}$ & $\begin{array}{c}\text { Job } \\
\text { satisfaction }\end{array}$ \\
\hline \multirow{3}{*}{ Self-awareness } & 0.00 & 0.33 & 0.43 & 0.25 & 0.40 & 0.23 & 0.22 \\
& 0.00 & 0.57 & 0.68 & 0.47 & 0.65 & 0.45 & 0.43 \\
& 0.25 & 0.80 & 0.87 & 0.68 & 0.83 & 0.68 & 0.67 \\
\hline \multirow{3}{*}{ Self-management } & 0.58 & 0.00 & 0.42 & 0.43 & 0.55 & 0.33 & 0.40 \\
& 0.83 & 0.00 & 0.65 & 0.68 & 0.80 & 0.57 & 0.63 \\
& 0.97 & 0.25 & 0.85 & 0.87 & 0.98 & 0.80 & 0.85 \\
\hline \multirow{3}{*}{ Self-motivation } & 0.52 & 0.45 & 0.00 & 0.40 & 0.42 & 0.40 & 0.47 \\
& 0.77 & 0.70 & 0.00 & 0.65 & 0.65 & 0.65 & 0.70 \\
Empathy & 0.95 & 0.92 & 0.25 & 0.83 & 0.87 & 0.87 & 0.90 \\
& 0.43 & 0.43 & 0.38 & 0.00 & 0.47 & 0.40 & 0.47 \\
& 0.68 & 0.68 & 0.62 & 0.00 & 0.72 & 0.65 & 0.72 \\
Social skills & 0.87 & 0.87 & 0.82 & 0.25 & 0.90 & 0.87 & 0.90 \\
\hline \multirow{2}{*}{ Organizational } & 0.45 & 0.43 & 0.57 & 0.48 & 0.00 & 0.33 & 0.32 \\
commitment & 0.70 & 0.68 & 0.82 & 0.73 & 0.00 & 0.57 & 0.55 \\
& 0.90 & 0.87 & 0.97 & 0.90 & 0.25 & 0.80 & 0.78 \\
\hline \multirow{2}{*}{ Job satisfaction } & 0.47 & 0.45 & 0.52 & 0.52 & 0.32 & 0.00 & 0.52 \\
& 0.72 & 0.68 & 0.77 & 0.77 & 0.55 & 0.00 & 0.77 \\
& 0.90 & 0.88 & 0.97 & 0.93 & 0.80 & 0.25 & 0.90 \\
\hline
\end{tabular}

- Step 4: Determination and analysis of structural model; The linear scale transformation used here is a 
normalization formulae aimed at conversion of the scale of criteria into a comparable scale, which is shown in Table 4. It should be mentioned that before identifying cause and effect variables, a threshold value was defined for further clarification and elimination of weak influences between the variables. To do so, the minimum and maximum scores obtained from the overall relation matrix were subtracted from each other and then it was divided into 10 equal steps. Accordingly, the values within the range of the tenth step (0.9 to 1.0) were selected as considerable influence. It should be noted that the aforementioned tenth step was selected for high influence intensity (0ver 90\%), while the range of the sixth to ninth step (0.5 to 0.9 ) was selected as medium influence intensity, and the range of 0 to 0.5 (the first to the fifth step) for weak influence intensity. Table 4 provides the overall relation matrix before setting and applying the threshold value.

Table 4: Overall-relation matrix

\begin{tabular}{lccccccc}
\hline & $\begin{array}{c}\text { Self- } \\
\text { awareness }\end{array}$ & $\begin{array}{c}\text { Self- } \\
\text { management }\end{array}$ & $\begin{array}{c}\text { Self- } \\
\text { motivation }\end{array}$ & Empathy & $\begin{array}{c}\text { Social } \\
\text { skills }\end{array}$ & $\begin{array}{c}\text { Organizational } \\
\text { commitment }\end{array}$ & $\begin{array}{c}\text { Job } \\
\text { satisfaction }\end{array}$ \\
\hline \multirow{2}{*}{ Self-awareness } & 0.00670 & 0.03160 & 0.04110 & 0.02520 & 0.03680 & 0.02320 & 0.02266 \\
& 0.02020 & 0.06150 & 0.07130 & 0.05430 & 0.06780 & 0.05110 & 0.05129 \\
& 0.06450 & 0.10430 & 0.11104 & 0.09500 & 0.11154 & 0.09340 & 0.09380 \\
\hline \multirow{2}{*}{ Self-management } & 0.05374 & 0.00820 & 0.04140 & 0.04150 & 0.05040 & 0.03230 & 0.03861 \\
& 0.08746 & 0.02315 & 0.07409 & 0.07460 & 0.08340 & 0.06380 & 0.07030 \\
& 0.12477 & 0.06865 & 0.11635 & 0.11430 & 0.12510 & 0.10780 & 0.11320 \\
\hline \multirow{3}{*}{ Self-motivation } & 0.04860 & 0.04250 & 0.00910 & 0.03890 & 0.04020 & 0.03760 & 0.04360 \\
& 0.08240 & 0.07551 & 0.02469 & 0.07200 & 0.07232 & 0.06960 & 0.07505 \\
& 0.12372 & 0.11906 & 0.07103 & 0.11210 & 0.11684 & 0.11270 & 0.11702 \\
\hline \multirow{3}{*}{ Empathy } & 0.04213 & 0.04109 & 0.03847 & 0.00800 & 0.04378 & 0.03750 & 0.04340 \\
& 0.07614 & 0.07410 & 0.07114 & 0.02280 & 0.07683 & 0.06950 & 0.07605 \\
Social skills & 0.11724 & 0.11500 & 0.11369 & 0.06750 & 0.12119 & 0.11240 & 0.11909 \\
\hline \multirow{2}{*}{ Organizational } & 0.04357 & 0.04121 & 0.05230 & 0.04490 & 0.00820 & 0.03260 & 0.03232 \\
commitment & 0.07750 & 0.07420 & 0.08530 & 0.07780 & 0.02310 & 0.06350 & 0.06410 \\
\hline \multirow{2}{*}{ Job satisfaction } & 0.11935 & 0.11473 & 0.12401 & 0.11610 & 0.06941 & 0.10850 & 0.10790 \\
\hline & 0.04527 & 0.04291 & 0.04889 & 0.04796 & 0.03320 & 0.00730 & 0.04790 \\
& 0.07957 & 0.07506 & 0.08274 & 0.08111 & 0.06590 & 0.02140 & 0.08070 \\
& 0.12060 & 0.11716 & 0.12531 & 0.11978 & 0.11251 & 0.06660 & 0.11762 \\
\hline
\end{tabular}

According to the calculations performed for the influences with an intensity over $90 \%$, the acceptable range in the fuzzy method was found to be from 0.11343 to 0.12531 . Thus, the influence intensities outside this range were deleted from the matrix. The results are shown in Table 5.

Table 5: Overall-relation matrix after introduction of threshold

\begin{tabular}{|c|c|c|c|c|c|c|c|}
\hline & $\begin{array}{c}\text { Self- } \\
\text { awareness }\end{array}$ & $\begin{array}{c}\text { Self- } \\
\text { management }\end{array}$ & $\begin{array}{c}\text { Self- } \\
\text { motivation }\end{array}$ & Empathy & $\begin{array}{l}\text { Social } \\
\text { skills }\end{array}$ & $\begin{array}{c}\text { Organizational } \\
\text { commitment }\end{array}$ & $\begin{array}{c}\text { Job } \\
\text { satisfaction }\end{array}$ \\
\hline \multicolumn{8}{|l|}{ Self-awareness } \\
\hline Self-management & $\begin{array}{l}0.05374 \\
0.08746 \\
0.12477\end{array}$ & & & & $\begin{array}{l}0.05040 \\
0.08340 \\
0.12510\end{array}$ & & \\
\hline Self-motivation & $\begin{array}{l}0.04860 \\
0.08240 \\
0.12372\end{array}$ & & & & & & \\
\hline Empathy & & & & & $\begin{array}{l}0.04378 \\
0.07683 \\
0.12119\end{array}$ & & \\
\hline
\end{tabular}




\begin{tabular}{|c|c|c|c|c|c|c|c|}
\hline & $\begin{array}{c}\text { Self- } \\
\text { awareness }\end{array}$ & $\begin{array}{c}\text { Self- } \\
\text { management }\end{array}$ & $\begin{array}{c}\text { Self- } \\
\text { motivation }\end{array}$ & Empathy & $\begin{array}{l}\text { Social } \\
\text { skills }\end{array}$ & $\begin{array}{c}\text { Organizational } \\
\text { commitment }\end{array}$ & $\begin{array}{c}\text { Job } \\
\text { satisfaction }\end{array}$ \\
\hline \multirow{3}{*}{ Social skills } & 0.04357 & & 0.05230 & & & & \\
\hline & 0.07750 & & 0.08530 & & & & \\
\hline & 0.11935 & & 0.12401 & & & & \\
\hline \multirow{3}{*}{$\begin{array}{l}\text { Organizational } \\
\text { commitment }\end{array}$} & 0.04527 & & 0.04889 & 0.04796 & & & \\
\hline & 0.07957 & & 0.08274 & 0.08111 & & & \\
\hline & 0.12060 & & 0.12531 & 0.11978 & & & \\
\hline
\end{tabular}

\section{Job satisfaction}

Table 6: Final defuzzified matrix

\begin{tabular}{ccc|ccc|ccc|ccc|c|c}
\hline & Ri & \multicolumn{3}{c|}{ Ji } & \multicolumn{3}{c|}{ Ri+Ji } & & Ri-Ji & (Ri+Ji)def & (Ri-Ji)def \\
\hline 0.271 & 0.485 & 0.778 & 0.188 & 0.377 & 0.674 & 0.458 & 0.863 & 1.451 & -0.083 & 0.108 & 0.1 .04 & 0.924 & 0.098 \\
0.239 & 0.445 & 0.744 & 0.267 & 0.477 & 0.770 & 0.505 & 0.922 & 1.515 & -0.028 & -0.032 & -0.026 & 0.981 & -0.029 \\
0.270 & 0.479 & 0.777 & 0.260 & 0.472 & 0.772 & 0.531 & 0.951 & 1.550 & 0.010 & 0.008 & 0.005 & 1.011 & 0.007 \\
0.243 & 0.448 & 0.731 & 0.254 & 0.467 & 0.766 & 0.497 & 0.914 & 1.497 & -0.012 & -0.019 & -0.036 & 0.969 & -0.022 \\
0.244 & 0.451 & 0.764 & 0.255 & 0.465 & 0.760 & 0.499 & 0.916 & 1.524 & -0.011 & -0.014 & 0.004 & 0.980 & -0.007 \\
0.205 & 0.401 & 0.704 & 0.273 & 0.486 & 0.780 & 0.478 & 0.887 & 1.484 & -0.069 & -0.086 & -0.075 & 0.905 & -0.076 \\
0.235 & 0.437 & 0.733 & 0.209 & 0.401 & 0.709 & 0.443 & 0.838 & 1.442 & 0.026 & 0.035 & 0.024 & 0.908 & 0.028 \\
\hline
\end{tabular}

Figure 1 displays the cause and effect influences in the upper threshold of the fuzzy DEMATEL method.

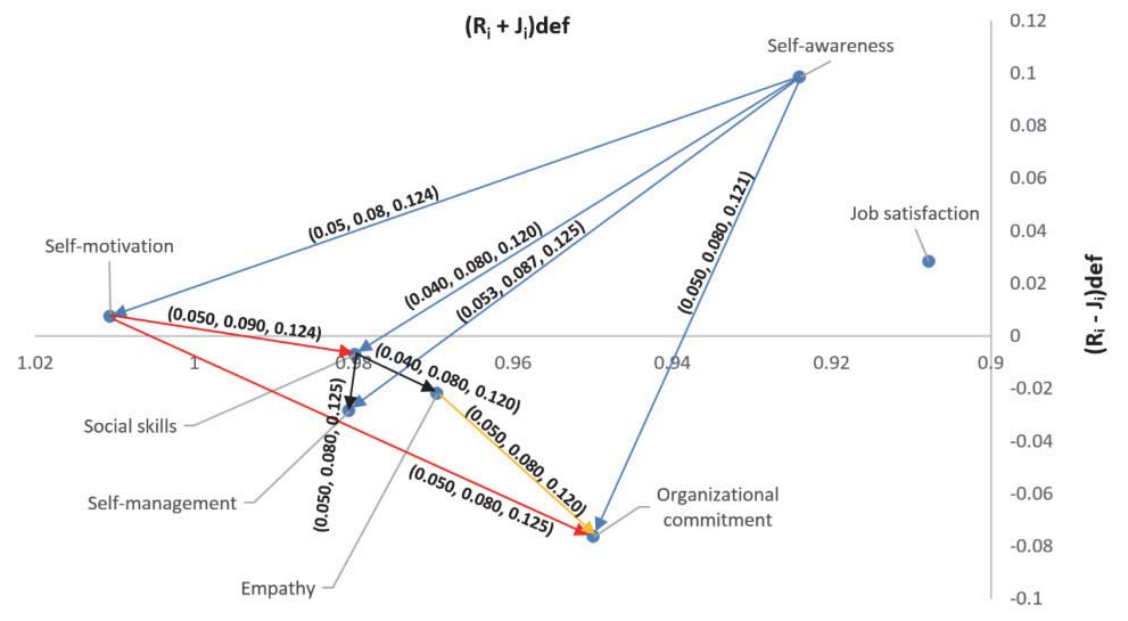

Figure 1. Causal diagram for fuzzy DEMATEL method

As mentioned, the horizontal axis demonstrates the importance or superiority of criteria and it could be seen from Figure 1 that among the cause variables, job satisfaction was of the least importance and self-motivation was of the greatest importance. Similarly, among the effect variables, organizational commitment and self-management are respectively attributed to the lowest and highest importance.

\section{Discussion}

According to Figure 1 and the accepted threshold of 90\%, the greatest influence was observed for self-awareness component on self-management, self-motivation, organizational commitment and social skills. It was also observed that the component of self-motivation had influence on organizational commitment and social skills. The component of social 
skills was of considerable influence over self-management and empathy, and finally the component of empathy had a considerable influence over organizational commitment. Furthermore, according to Table 6 which is also illustrated in Figure 1, among the relationships mentioned above, the strongest cause was seen for the influence of self-motivation over organizational commitment and the weakest one (in the category of high influence) was attributed to the influence of self-awareness on social skills.

As it could be seen from Figure 1, self-awareness component was of the greatest number of intense cause influences on other components, which implies the special attention managers should pay into this component. On the other side, as it was said, the horizontal axis represents importance or superiority of criteria. Accordingly, Figure 1 illustrates that among the components of emotional intelligence, self-motivation was of the greatest importance or superiority. In fact, the results state that self-motivation is like an engine that if it works properly, an accelerated growth of organizational commitment, social skills and even self-management and empathy would be achieved. As it was explained, self-motivation had its highest influence on organizational commitment and social skills. Therefore, human resource managers should pay particular attention to this component of emotional intelligence when recruiting new workforce. Among the cause variables, job satisfaction variable had the lowest influence while self-motivation was of the greatest. Likewise, among the effect variables, organizational commitment showed the least importance while the component of self-management depicted the greatest importance.

Due to the elimination of the influence of job satisfaction on organizational commitment upon thresholding, and also taking the importance and influence of job satisfaction on organizational commitment into consideration, the authors attempted to further explain it. By defining the threshold at $90 \%$ of influence, the influence intensity of job satisfaction on organizational commitment was rated as medium, i.e. $50 \%$ to $90 \%$. It should be noted that the acceptable range for medium threshold was about 0.09469 to 0.11919 . based on Table 4 , the influence intensity of job satisfaction on organizational commitment was 0.11762 .

\section{Conclusion}

The results of the present research showed that in the upper threshold, over $90 \%$ of influence intensity, the strongest cause variable was attributed to the component of self-awareness while the strongest effect variable (highest influencetaking) was organizational commitment. Component of self-awareness had the greatest cause influences on selfmanagement, self-motivation, organizational commitment and social skills, respectively. It was also observed that the component of self-motivation was of the greatest influence on organizational commitment and social skills, respectively. The component of social skills had considerable influences on self-management and empathy, respectively. Finally, the component of empathy was of considerable influence on the variable of organizational commitment. Among the mentioned relationships, the most intense cause was attributed to the influence of self-motivation on organizational commitment, while the least (within the upper threshold which indicates intense influences) was seen for the influence of self-awareness on social skills. Based upon the horizontal axis of Figure 1, which depicts the importance, it was seen that among the cause variables, self-motivation component was of the greatest importance and job satisfaction of the least. Also among the effect variables, the variable of organizational commitment had the least importance compared with all other variables and components. In the following, some suggestions are provided based on the results:

- The findings revealed that self-awareness component had the greatest influence on other variables and components. Thus, human resource managers should determine the status of this component and improve it utilizing training and education under a long-term planning, since employees having a higher self-awareness would have a truer feeling toward themselves, better know their strengths and weaknesses, have a higher self-confidence and act based on their abilities. Such employees more skillfully control problems in their lives and reach a deeper understanding of their real feelings toward the job they wanted to select. Since the selfawareness component of emotional intelligence is trainable, it is suggested to train employees in this dimension for improvement of their job satisfaction and organizational commitment. After self-awareness, the components of self-motivation, social skills, empathy and self-management were of the greatest influence organizational commitment, respectively. As a result, managers should pay careful attention to these dimensions and bring them into the training topics of their organizations.

- Prior to recruitment of new human resources and also at the time of employee promotion, human resource managers should pay attention to emotional intelligence topic and its components including self-motivation, since it was the most important cause variable according to Figure 1, in order to leverage organizational commitment and in turn organizational performance. Upon the arrival of an employee, a lot of costs are imposed into an organization in order to be able to use his/her knowledge and experience and realize its 
organizational strategies and goals. In other words, optimum absorption, preservation and utilization of employee capabilities should be in the principal agenda of every organization. According to the present findings, self-motivation is like an engine that upon proper functioning, could cause accelerated growth of organizational commitment, empathy, self-management and even social skills.

- The present results indicated that social skills component has an influence intensity over $90 \%$ on the components empathy and self-management. Taking a look at the responsibilities of managers, and at empathy with employees and having self-management in difficult situations as two prominent characteristics of a successful manager, social skills could be considered as one of the most important features of managerial positions in organizations. Thus, when promoting employees, social skills could be taken as one of the important parameters of the applicants. Also, for growth of this component of emotional intelligence, it is necessary to have appropriate training courses by management.

\section{References}

Alavi, S. Z., Mojtahedzadeh, H., Amin, F., \& Savoji, A. P. (2013). Relationship Between Emotional Intelligence and Organizational Commitment in Iran's Ramin Thermal Power Plant. Procedia-Social and Behavioral Sciences, 84, 815-819.

Bakotić, D. F., \& Babić, T. (2013). C, Relationship between Working Conditions and Job Satisfaction: The Case of Croatian Shipbuilding Company. International Journal of Business and Social Science, 4(2), 206-213.

Bazvand, K., Kashef, M. M., \& Esmaeili, M. R. (2013). Relationship between emotional intelligence, organizational commitment, and job satisfaction of employees of the Department of Physical Education of Lorestan province. Journal of Sport Management, 5(4), 123-145. (in Persian)

Chan, D. W. (2006). Emotional intelligence and components of burnout among Chinese secondary school teachers in Hong Kong. Teaching and Teacher Education, 22(8), 1042-1054.

Gholami, B., Shams, S., \& Amoozadeh, M. (2013). The Investigation of the Relationship between Emotional Intelligence. Job Satisfaction and Organizational Commitment of Personnel in Banks and Financial Institutions of Darrehshahr City. International Research Journal of Applied and Basic Sciences, 6(10), 1499-1504.

Hsieh, T. Y., Lu, S. T., \& Tzeng, G. H. (2004). Fuzzy MCDM Approach for Planning and Design Tenders Selection in Public Office Buildings. International Journal of Project Management, 22(7), 573-584.

Jordan, P. J., Ashkanasy, N. M., Härtel, C. E., \& Hooper, G. S. (2002). Workgroup emotional intelligence: Scale development and relationship to team process effectiveness and goal focus. Human Resource Management Review, 12(2), 195-214.

Kay, M. B. (2007). The Effect of Prior Commitment on Group Conflict in Judgemental Tasks (Master Of Applied Science In Management Sciences). University Of Waterloo, Ontario, Canada.

Li, R. J. (1999). Fuzzy method in group decision making. Computers and Mathematics with Applications, 38(1), 91-101.

Lin, C.-J., \& Wu, W.-W. (2008). A causal analytical method for group decision-making under fuzzy environment. Expert Systems with Applications, 34(1), 205-213.

Mayer, J.-S., \& Salovey, Y. (1997). What is emotional intelligence. In Emotional Development and Emotional Intelligence: implications for educators (pp. 3-31). New York.

Nazarian Madavani, A., \& Mokhtari Dinani, M. (2013). The relationship between job satisfaction, organizational commitment, and emotional intelligence of the staff of Physical Education Offices of universities in Tehran. Journal of Applied Researches in Sports Management, 2(2), 43-56. (in Persian)

Othman, S., \& Anugerah, R. (2009). Effects of Emotional intelligence and career commitment on career success. Malaysian Management Review, 37(1), 46-52.

Öztürk, A., \& Deniz, M. E. (2008). Analysis of Emotional intelligence Job satisfaction and Burnout Levels of preschool Teachers According to some variables. Elementary Education Online, 7(3), 578-599.

Qasim, S., Cheema, F. E. A., \& Syed, N. A. (2012). Exploring Factors Affecting Employees' Job Satisfaction at Work. Journal of Management and Social Sciences, 8(1), 31-39.

Schlechter, A. F., \& Strauss, J. J. (2008). Leader emotional intelligence, transformational leadership, trust and team commitment: testing a model within a team context: empirical research. SA Journal of Industrial Psychology, 34(1), 42-53.

Taboli, H., Ahmadipanah, M., Jalilian, O., Hasani, S. R., Jalilian, H., Jalilian, H., ... Tung-HsingChiang, S. (2013). Job satisfaction as a mediator in relationship between emotional intelligence, organizational commitment in employees' Kerman universities. Life Science Journal, 10(1), 1-10.

Utami, A. F., Bangun, Y. R., \& Lantu, D. C. (2014). Understanding the Role of Emotional Intelligence and Trust to the Relationship between Organizational Politics and Organizational Commitment. Procedia-Social and Behavioral Sciences, 115, 378-386.

Wooldridge, A. (2000, March 5). Come Back, Company Man! The New York Times. Retrieved from http://www.nytimes.com/2000/03/05/magazine/come-back-company-man.html 